\title{
Exploring the geographical distribution of cryptosporidiosis in the cattle population of Southern Ontario, Canada, 2011-2014
}

\author{
Andrea Nwosu, ${ }^{1}$ Olaf Berke, ${ }^{1}$ David L. Pearl, ${ }^{1}$ Lise A. Trotz-Williams ${ }^{2}$ \\ ${ }^{1}$ Department of Population Medicine, Ontario Veterinary College, University of Guelph, Guelph; \\ ${ }^{2}$ Wellington-Dufferin Guelph Public Health, Guelph, Canada
}

\begin{abstract}
Cryptosporidiosis is an infectious disease of relevance to the cattle industry. The southern region of the Canadian province of Ontario is characterised by widespread cattle farming that is a key contributor to the Canadian dairy industry. Given Ontario's key
\end{abstract}

Correspondence: Andrea Nwosu, Department of Population Medicine, Ontario Veterinary College, University of Guelph, 50 Stone Road E, Guelph, ON, Canada N1G 2W1.

Tel. +1.616.857.0601.

E-mail: anwosu@uoguelph.ca

Acknowledgements: the authors would like to thank the Animal Health Laboratory at the University of Guelph for providing the data and the Ontario Veterinary College (Guelph, ON, Canada), and the R. A. Curtis graduate bovine scholarship for providing funding for this project.

Key words: Cryptosporidium; Cattle; Southern Ontario; Geospatial; Spatial statistics.

Contributions: AN designed the study objectives; she performed the data cleaning, management and analysis; she interpreted the results and was the principal author. OB provided assistance on study design and objective, data analysis and interpretation as well as critical feedback and edits. DLP, LTW provided assistance on study design and interpretation as well as critical feedback and edits.

Conflict of interest: the authors declare no potential conflict of interest.

Funding: the work was supported by the R. A. Curtis graduate bovine scholarship and the Ontario Veterinary College at the University of Guelph.

Conference presentation: part of this paper was presented at the Canadian Association of Veterinary Epidemiology and Preventive Medicine, 2017 June 5-6, Calgary, Alberta, Canada.

Received for publication: 14 February 2019.

Revision received: 13 April 2019.

Accepted for publication: 7 May 2019.

${ }^{\circ}$ Copyright: the Author(s), 2019

Licensee PAGEPress, Italy

Geospatial Health 2019; 14:769

doi:10.4081/gh.2019.769

This article is distributed under the terms of the Creative Commons Attribution Noncommercial License (CC BY-NC 4.0) which permits any noncommercial use, distribution, and reproduction in any medium, provided the original author(s) and source are credited. role in the Canadian dairy industry and the potential impact that cryptosporidiosis can have on cattle operations, identifying areas of increased risk for bovine cryptosporidiosis is important. The primary goal of this study was to explore the distribution of bovine cryptosporidiosis, across the geographical areas served by the 29 Public Health Units (PHUs) of Southern Ontario, in the period 2011-2014. Laboratory data on bovine cryptosporidiosis were collected from the Animal Health Laboratory at the University of Guelph, Canada. Using veterinary clinic locations as a proxy for farm location, choropleth and isopleth maps were produced. Highrisk clusters of bovine cryptosporidiosis were identified using the flexible spatial scan test. Assessment of the potential for spatial misclassification bias resulting from a proxy location variable was conducted. The overall raw farm-level prevalence of bovine cryptosporidiosis was $45 \%$ [95\% confidence interval, CI: $42 \%-48 \%$ ]. A cluster was identified in the central-west region of Southern Ontario (relative risk 1.30 [95\% CI: 1.07-1.54, P=0.026]) meaning that cattle in the areas served by the Bruce-Grey-Owen Sound, Huron, Wellington-Dufferin Guelph and Waterloo PHUs were at a higher risk for infection. Given that this area is known for having a high-density of dairy cattle, it should be considered as a target for further surveillance.

\section{Introduction}

Cattle farming operations are very common in the southern region of Ontario: 97\% of all Ontario dairy farms are located in Southern Ontario, a region that represents only $15 \%$ of the provincial land mass area (Statistics Canada, 2014; Bishop-Williams et al., 2016; Environmental Management Branch, 2016; Statistics Canada and Canadian Dairy Commission, 2016). Geographical areas with a high density of livestock, such as Southern Ontario, are often at an increased risk for the spread of infectious diseases amongst the animals (Buhnerkempe et al., 2014). On a broader scale, the occurrence of zoonotic infectious diseases within these areas pose an additional risk to both human health and the environment, especially where there is also a high human population density as in Southern Ontario. Thus, identifying areas at risk for infectious diseases is important for targeted control and prevention of these diseases in human and animal populations.

Cryptosporidium is a ubiquitous protozoan parasite and the causal agent of cryptosporidiosis, a potentially lethal diarrheal disease that is known to affect cattle and a wide range of hosts (O’Donoghue, 1995; Abeywardena et al., 2015). Of the 26 species of Cryptosporidium currently identified, cattle are the primary hosts of Cryptosporidium andersoni, Cryptosporidium bovis, Cryptosporidium ryanae and Cryptosporidium parvum. Epidemiologically, C. parvum is often regarded as the most impor- 
tant species because of its primary role in the occurrence of cryptosporidiosis in young calves and in zoonotic infections in humans (Fayer et al., 2008; Peter et al., 2015). Infections in cattle occur through the transmission of oocysts by the faecal-oral route, either directly through host-to-host contact or indirectly through contaminated environments including food and water supplies (O’Donoghue, 1995; Peter et al., 2015). Cryptosporidium predominantly affects pre- to post-weaned dairy calves and is a primary cause of neonatal diarrhoea (O'Donoghue, 1995; Sivajothi et al., 2014; Abeywardena et al., 2015). Though infections do occur in adult cattle, they are often mild or asymptomatic (O'Donoghue, 1995; Sivajothi et al., 2014; Abeywardena et al., 2015). Clinical signs in cattle can vary from acute to chronic diarrhoea, with dehydration, fever, anorexia, weight loss, depression, dullness and bloating (Abeywardena et al., 2015). In some cases, complications can result in mortality (Ouchene et al., 2016). Currently, there is no effective treatment available for cryptosporidiosis and prevention remains a critical intervention in the management of this calf disease (Peter et al., 2015).

Several studies on the prevalence of Cryptosporidium in Canadian beef and dairy cattle have been conducted in British Columbia (Olson et al., 1997), Manitoba (Mann et al., 1986), Ontario (Trotz-Williams et al., 2005a, 2007), Québec (Ruest et al., 1998) and Prince Edward Island (Coklin et al., 2009). Farm-level and within-farm (calf-level) prevalence estimates have been reported to range from $36.4 \%$ to $88.7 \%$ of farms and $6.2 \%$ to $64 \%$ of calves on farms, respectively, suggesting that Cryptosporidium mostly C. parvum (Trotz-Williams et al., 2006) - is ubiquitous in Canadian cattle herds (Mann et al., 1986; Olson et al., 1997; Ruest et al., 1998; Trotz-Williams et al., 2005a; Coklin et al., 2009). Given the key role that Ontario plays in the Canadian dairy industry, the potential impact that cryptosporidiosis can have on Ontario cattle operations, and the public health risk posed by zoonotic transmission of this parasite, it is important to identify areas at increased risk for bovine cryptosporidiosis.

The objective of this study was to explore the spatial distribution of bovine cryptosporidiosis from 2011 to 2014, using laboratory diagnostic records from the University of Guelph's Animal Health Laboratory (AHL), across the areas served by the 29 local public health units (PHUs) of Southern Ontario.

\section{Materials and Methods}

\section{Study area}

Southern Ontario (Figure 1) is the primary and most densely populated part of Canada with respect to cattle farming, with an estimated cattle population of 1,622,949 in 2014 (Statistics Canada, 2014; Statistics Unit, 2017). Located south of Algonquin Park and stretching approximately $600 \mathrm{~km}$ in the north to south and east to west direction, Southern Ontario houses approximately $89 \%$ and 94\% of Ontario's human and bovine populations, respectively (Statistics Canada, 2014; Statistics Unit, 2017).

\section{Data collection}

Diagnostic laboratory data on 1,737 bovine specimens (from 1,235 farms in Ontario - both dairy and beef) tested for Cryptosporidium from January 1, 2011 to December 31, 2014, were obtained from the AHL at the University of Guelph. The specimens had all been submitted from symptomatic cattle. The laboratory dataset included variables indicating the number of samples tested per farm (range 1-5), number of positive Cryptosporidium specimens, date of submission, breed, commodity description, the servicing veterinarian's clinic city and postal code and, where available, the farm owner's postal code. No street addresses were available in the dataset. The AHL uses standard sucrose wet mount testing for ante mortem diagnosis of Cryptosporidium. This is a diagnostic test that identifies the presence of Cryptosporidium but does not provide species identification. It involves concentrating a faecal sample with Sheather's solution prior to detecting the presence of oocysts in the prepared sample by microscopy (Trotz-Williams et al., 2005b). The sensitivity and specificity of this diagnostic method is reported to be 88.6\% [95\% confidence interval, CI: $80.1 \%-94.4 \%$ ] and $93.8 \%$ [95\% CI: 86.0\%-97.9\%], respectively (Trotz-Williams et al., 2005b).

\section{Estimation of prevalence}

Case-level data (specimens tested) were aggregated to farmlevel using submission identification (ID). Using the 2015 Postal Code Conversion File (PCCF; Statistics Canada, 2016) and R version 3.2.3, farms from which calves had been tested for bovine cryptosporidiosis were assigned and aggregated to their respective PHU area based on the postal code of the servicing veterinarian's clinic since the farm postal code was only available for $30 \%(n=360)$ of all farms tested in the study area over the study period $(n=1,207)$. For each PHU area, the true raw, farm-level period prevalence of bovine cryptosporidiosis (i.e. the percentage of tested farms in each PHU area with at least one positive test) was determined for the four-year study period. The term true prevalence refers to estimates adjusted for diagnostic sensitivity and specificity. First, the overall apparent (unadjusted) farm-level disease prevalence over the four-year study period was estimated for each area from the total number of positive farms divided by the total number of tested farms in that PHU area. Using the known sensitivity and specificity of the diagnostic test, the

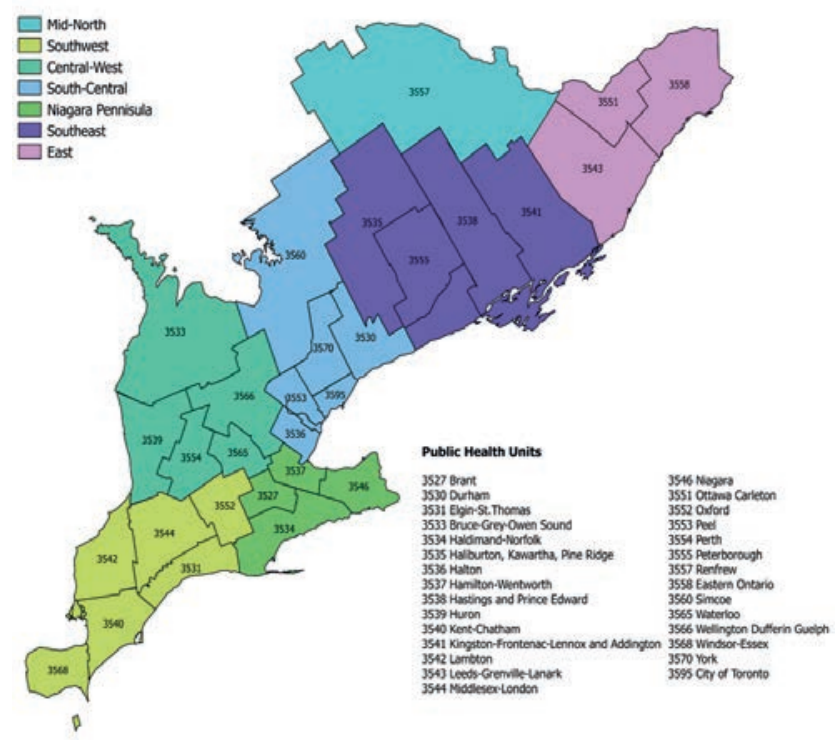

Figure 1. Map of the regions of Southern Ontario and areas within those regions served by individual Public Health Units in Southern Ontario (geographical distributions set by the Ontario Ministry of Government and Consumer Services, 2017). 
true farm-level prevalence of bovine cryptosporidiosis within each PHU area was then estimated. These adjusted (true) prevalence estimates were used for all subsequent analyses and are hereafter referred to as prevalence or farm-level prevalence. The general formula (Eq. 1) used was the one used by Dohoo et al. (2012):

$$
T P=\frac{A P+S p-1}{S e+S p-1}
$$

where $T P$, estimated true prevalence; $A P$, apparent (unadjusted) prevalence; $S p$, specificity of the diagnostic test; and $S e$, sensitivity of the diagnostic test. Approximate and exact CIs were estimated for each prevalence estimate. For PHU areas with sample sizes $\leq 200$ tested farms, exact CIs adjusted for the sensitivity and specificity were estimated using Blaker's method (Reiczigel et al., 2010). For areas with sample sizes $\geq 200$, the approximate CIs, adjusted for sensitivity and specificity, were estimated using the normal approximation method (Rogan and Gladen, 1978).

Using R package spdep (Bivand et al., 2015), the raw farm-level prevalence for each PHU area was smoothed using empirical Bayesian smoothing in order to standardise the estimates for spatial and regional variation in the sample size (Berke, 2001; Hampton et al., 2011; Bivand et al., 2013). The general formula (Marshall, 1991) is the following (Eq. 2):

$G B S\left(\mathrm{u}_{i}\right)=w\left(\mathrm{u}_{i}\right) z\left(\mathrm{u}_{i}\right)+\left[1-w\left(\mathrm{u}_{i}\right)\right] \mathrm{m}^{*} \quad i=1, \ldots \mathrm{N}$

Eq. 2

where $\mathrm{u}_{i}=1, \ldots, \mathrm{N}$ is the index and number of regions; $z\left(\mathrm{u}_{i}\right)=$ the raw prevalence; $m^{*}=$ the global prevalence; and $w\left(\mathrm{u}_{i}\right)=$ the Bayes shrinkage factor.

For the smoothing, it was assumed that the farm-level prevalence of bovine cryptosporidiosis followed a binomial distribution. Parallel boxplots were used to show the shrinkage effect that resulted from smoothing the raw prevalence estimates.

\section{Mapping and spatial analysis}

\section{Choropleth and isopleth mapping}

Using R package maptools (Bivand and Lewin-Koh, 2013), the raw and smoothed farm-level prevalence estimates were visualised by creating choropleth maps which were used as an initial visualisation of the spatial variation of bovine cryptosporidiosis across Southern Ontario. Though choropleth maps are useful for initial examination of spatial risk variation, issues of visual bias created by the aggregation of data into administrative regions of varying sizes makes it difficult to effectively interpret spatial patterns (Berke, 2001; Goovaerts, 2006). Therefore, isopleth risk maps for the overall study period, based on Bayesian adjusted prevalence estimates, were also produced using $\mathrm{R}$ package geoR in R, v. 3.2.4 (Ribeiro and Diggle, 2001; Berke, 2005).

\section{Cluster detection}

Flexible spatial scan statistic (Tango and Takahashi, 2005) was used to detect high-risk clusters of bovine cryptosporidiosis for the study period. For the purpose of this study, a disease cluster was defined as a higher than expected number of cases occurring close together in space, and the null hypothesis for each iteration was that the risk of bovine cryptosporidiosis within the window was the same as outside the window. Since the flexible spatial scan test was used to detect hot-spots of disease clusters, the alternative hypothesis was that the risk of bovine cryptosporidiosis was higher within the win- dow compared to outside the window (i.e., a one-sided test). Locations of detected clusters were indicated on a choropleth map. R, v. 3.2.4 package smerc (French, 2015) was used to conduct the flexible spatial scan test. For the scan test, a Bernoulli model was used with the raw prevalence estimates. A significance level of $\alpha=0.05$ was chosen and 999 Monte Carlo simulations were used to estimate the P-value. Given that the number of PHUs in Southern Ontario is small $(\mathrm{n}=29)$, a pre-set maximum cluster size of $k=5$ regions was selected as an alternative to the default setting of 10 ; a $k$ number of 10 might cover more than $50 \%$ of the total population size (i.e. the total number of farms). All statistical analyses were conducted in R, v. 3.2.4 and RStudio, v. 1.0.44 (R Core Team, 2016; RStudio Team, 2016).

\section{Assessment of spatial misclassification}

An assessment of the potential for spatial misclassification resulting from the use of veterinary clinic location as a proxy for farm location was conducted. For the subset of tested farms that included both the veterinarian and farm location, farms were assigned and aggregated to their respective PHU area based on the farm's postal code. For each PHU area, the proportion of farms that were located in the same (or adjacent) PHU area was then determined and compared, as measure of misclassification, to the proportions assigned based on clinic location.

\section{Results}

Twenty-eight of the 1,235 farms tested were removed from the study because their related addresses were outside of the defined study area. Overall, the raw farm-level prevalence of bovine cryptosporidiosis in Southern Ontario was estimated to be $45 \%$ [95\% CI: $42 \%-48 \%$ ] - not very different from the unadjusted raw prevalence; 541 of the 1207 farms included in the study tested positive. The raw farm-level prevalence estimates of the $29 \mathrm{PHU}$ areas ranged from 0\% [95\% CI: $0-8$ ] to $62 \%$ [95\%CI: $35 \%-87 \%$ ] of farms, with the highest raw prevalence estimates found in the areas served by the Chatham-Kent and Peterborough County PHUs and the lowest in those served by the Hamilton-Wentworth and Middlesex-London PHUs (Table 1). No samples had been submitted for testing from farms in four PHU areas: Halton, Niagara, Windsor-Essex and the City of Toronto. The smoothed farm-level prevalence showed less variability, ranging from $38 \%$ to $53 \%$ (Table 1). The highest

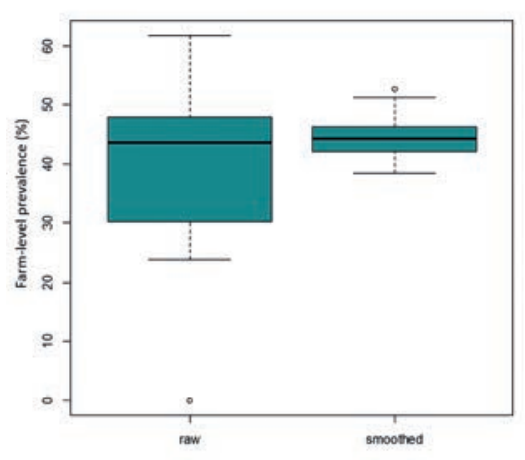

Figure 2. Parallel boxplot of raw and Empirical Bayesian smoothed farm-level prevalence of bovine cryptosporidiosis in Southern Ontario, 2011-2014. 
smoothed prevalence estimates were observed in the OttawaCarleton and Waterloo PHU areas, while Simcoe-Muskoka and Kingston-Frontenac-Lennox-Addington PHU areas had the lowest. The shrinkage effect on the regional prevalence estimates can be seen in the parallel boxplot shown in Figure 2: the extreme high and low prevalence rates tended to shrink towards the distribution centre (Figure 2).

Based on the choropleth maps for the raw and smoothed preva- lence rates, PHU areas with higher farm-level prevalence of bovine cryptosporidiosis were predominately located in the Central West, Southeast and East regions of Southern Ontario (Figures 3 and 4). Three areas of potential increased risk were also visually identified in the isopleth map (Figure 5): two adjoining ones that spanned the Central West and Southeast regions and a third located in the East region; these areas overlapped with PHU areas that had higher farm-level prevalence estimates.

Table 1. Raw and smoothed (empirical Bayesian) true (prevalence estimate adjusted for sensitive and specificity of diagnostic test used) farm-level prevalence estimates of bovine cryptosporidiosis for the 29 Public Health Unit areas of Southern Ontario, 2011-2014.

$\begin{array}{lll}\text { PHU Area } & \text { Prevalence in \% } & \text { Farms } \\ \text { Number } & \text { Name }[95 \% \text { CI }] & \text { Bayesian }\end{array}$

\section{Mid North Region}

Renfrew County and District

Southwest Region

\begin{tabular}{llc}
3531 & Elgin-St Thomas & $46[14-79]$ \\
3540 & Chatham-Kent & $62[18-90]$ \\
\hline 3542 & Lambton County & $44[9-82]$ \\
3544 & Middlesex-London & $0[0-8]$ \\
\hline 3552 & Oxford County & $46[40-52]$ \\
3568 & Windsor-Essex County & $\mathrm{N} / \mathrm{A}$
\end{tabular}

$40 \quad 29$

\begin{tabular}{cc}
45 & 9 \\
47 & 7 \\
45 & 7 \\
44 & 2 \\
46 & 228 \\
N/A & 0 \\
\hline
\end{tabular}

\begin{tabular}{lllll}
3533 & Bruce-Grey-Owen Sound & $39[27-52]$ & 42 & 62 \\
3539 & Huron County & $57[42-70]$ & 50 & 53 \\
\hline 3554 & Perth District & $48[31-66]$ & 46 & 35 \\
3565 & Waterloo Region & $56[47-64]$ & 53 & 147 \\
\hline 3566 & Wellington-Dufferin-Guelph & $47[39-55]$ & 47 & 164
\end{tabular}

South-Central Region

\begin{tabular}{|c|c|c|c|c|}
\hline 3530 & Durham Region & $50[30-74]$ & 46 & 21 \\
\hline 3536 & Halton Region & N/A & N/A & 0 \\
\hline 3553 & Peel Region & $35[15-43]$ & 40 & 43 \\
\hline 3560 & Simcoe Muskoka District & $24[9-42]$ & 38 & 27 \\
\hline 3570 & York Region & $30[18-47]$ & 39 & 42 \\
\hline 3595 & City of Toronto & N/A & N/A & 0 \\
\hline \multicolumn{5}{|c|}{ Niagara Peninsula } \\
\hline 3527 & Brant County & $27[4-71]$ & 43 & 7 \\
\hline 3534 & Haldimand-Norfolk & $43[30-59]$ & 44 & 50 \\
\hline 3537 & Hamilton-Wentworth & $0[0-7]$ & 43 & 3 \\
\hline 3546 & Niagara Region & N/A & N/A & 0 \\
\hline \multicolumn{5}{|c|}{ Southeast Region } \\
\hline 3535 & Haliburton-Kawartha-Pine Ridge & $41[5-85]$ & 45 & 5 \\
\hline 3538 & Hastings and Prince Edward Counties & $44[29-62]$ & 44 & 38 \\
\hline 3541 & Kingston-Frontenac-Lennox and Addington & $24[9-42]$ & 38 & 27 \\
\hline 3555 & Peterborough County & $62[35-87]$ & 48 & 14 \\
\hline \multicolumn{5}{|c|}{ East Region } \\
\hline 3543 & Leeds-Grenville-Lanark District & $44[32-55]$ & 44 & 76 \\
\hline 3551 & Ottawa Carleton & $60[44-74]$ & 51 & 45 \\
\hline 3558 & Eastern Ontario & $35[24-48]$ & 40 & 66 \\
\hline
\end{tabular}

PHU, Public Health Unit; Cl, confidence interval; N/A, not applicable. 
One high-risk cluster of cryptosporidiosis was identified; this was in the Central West region of Southern Ontario; the relative risk of this cluster was 1.30 [95\%CI: $1.07-1.54, \mathrm{P}=0.026]$. The PHU areas of Bruce-Grey-Owen Sound, Wellington-Dufferin Guelph, Huron and Waterloo were within the cluster, suggesting that the cattle population in these areas were at a $30 \%$ higher risk for infection than cattle populations in other areas of Southern Ontario (Figure 6).

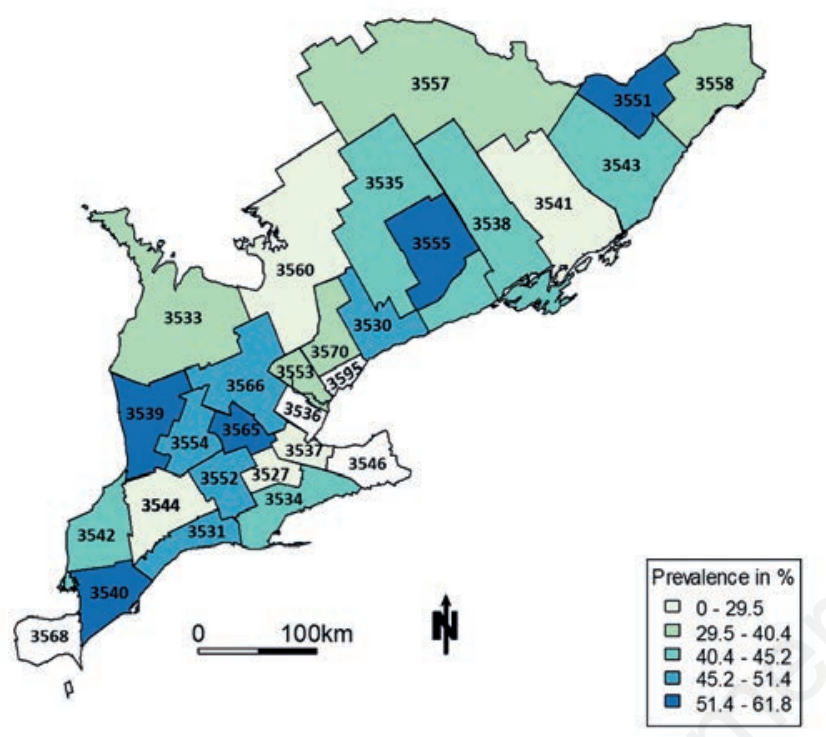

Figure 3. Choropleth map of the spatial distribution of raw farmlevel prevalence of bovine cryptosporidiosis in 29 Public Health Unit areas of Southern Ontario, 2011-2014.

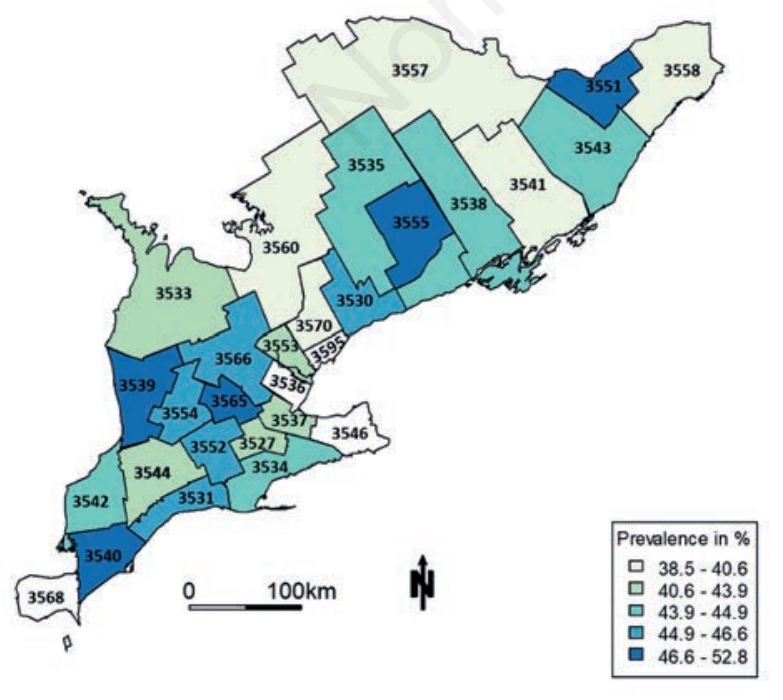

Figure 4. Choropleth map of the spatial distribution of smoothed farm-level prevalence of bovine cryptosporidiosis in 29 Public Health Unit areas of Southern Ontario, 2011-2014.
Three hundred and sixty of the 1,207 farms, located in all but four of the 29 PHU areas, were used for the spatial misclassification analysis. Of these 360 farms, $81 \%$ of clinic locations were either within the same $(54 \%)$ or adjacent $(27 \%)$ PHU area as that of the cattle owner. The remaining $19 \%$ of clinic locations were located in PHU areas that were neither adjacent nor within the same PHU area as the cattle owner. In 5 of the 29 PHU areas (Hastings-Prince Edward, Kingston-Frontenac-Lennox-

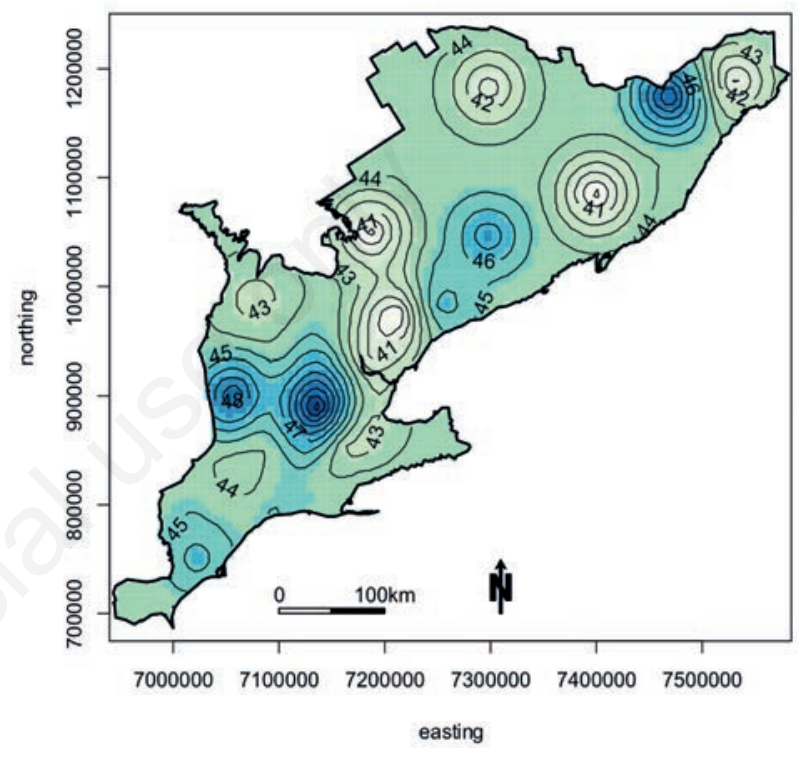

Figure 5. Isopleth map of the latent risk distribution of cryptosporidiosis among cattle of Southern Ontario, 2011-2014.

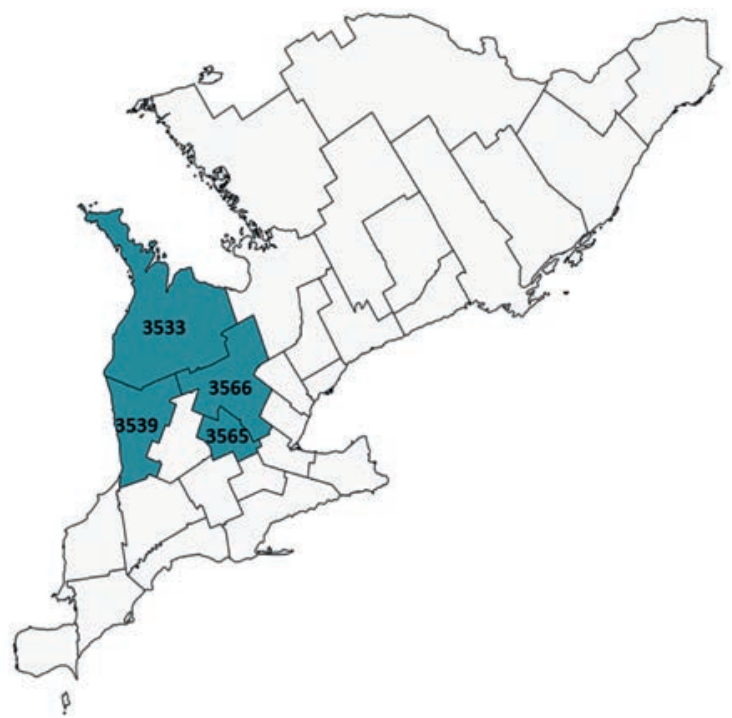

Figure 6. Location of high-risk cluster of bovine cryptosporidiosis in 29 Public Health Unit areas of Southern Ontario, 2011-2014. 
Addington, Lambton, Peterborough and Renfrew), all cattle farms were located within the same PHU area as the clinics from which the specimen(s) had been submitted for testing. In four areas (York, Haliburton-Kawartha-Pine Ridge, Middlesex-London, and Niagara), none of the farms were located within the same PHU areas as the clinics from which the specimens had been submitted. Overall, in $16 \mathrm{PHU}$ areas, $\geq 50 \%$ of the farms were located within the same PHU area as the submitting veterinarian (Table 2).

\section{Discussion}

The primary goal of this study was to describe and visualise the distribution of bovine cryptosporidiosis at the farm-level in the areas served by the 29 PHUs of Southern Ontario using spatial epidemiology methods. Results from the analysis indicate that bovine cryptosporidiosis is not only highly prevalent in Southern Ontario cattle populations, but also quite widespread. Overall, farms positive for

Table 2. Proportion of veterinary clinics located in the same or adjacent Public Health Unit area as the farm owner, Southern Ontario, 2011-2014.

\begin{tabular}{|c|c|c|c|c|}
\hline $\begin{array}{l}\text { Owner's PHU Area } \\
\text { Number }\end{array}$ & Name & $\begin{array}{l}\text { Proportion of veterinary } \\
\text { Within same PHU }\end{array}$ & $\begin{array}{l}\text { postal codes (\%) } \\
\text { Within an adjacent PHU }\end{array}$ & $\begin{array}{l}\text { Number } \\
\text { of farms }\end{array}$ \\
\hline \multicolumn{5}{|l|}{ Mid North Region } \\
\hline 3557 & Renfrew County and District & 100 & 0 & 5 \\
\hline \multicolumn{5}{|l|}{ Southwest Region } \\
\hline 3531 & Elgin-St Thomas & 67 & 0 & 3 \\
\hline 3540 & Chatham-Kent & $\mathrm{N} / \mathrm{A}$ & N/A & $\mathrm{N} / \mathrm{A}$ \\
\hline 3542 & Lambton County & 100 & 0 & 3 \\
\hline 3544 & Middlesex-London & 0 & 21 & 57 \\
\hline 3568 & Windsor-Essex County & N/A & N/A & N/A \\
\hline \multicolumn{5}{|l|}{ Central-West Region } \\
\hline 3533 & Bruce-Grey-Owen Sound & 80 & 13 & 15 \\
\hline 3539 & Huron County & 67 & 11 & 9 \\
\hline 3552 & Oxford County & 33 & 11 & 18 \\
\hline 3554 & Perth District & 55 & 45 & 10 \\
\hline 3565 & Waterloo Region & 60 & 40 & 15 \\
\hline 3566 & Wellington-Dufferin-Guelph & 70 & 29 & 91 \\
\hline \multicolumn{5}{|c|}{ South-Central Region } \\
\hline 3530 & Durham Region & 67 & 0 & 6 \\
\hline 3536 & Halton Region & $\mathrm{N} / \mathrm{A}$ & N/A & N/A \\
\hline 3553 & Peel Region & 63 & 38 & 8 \\
\hline 3560 & Simcoe Muskoka District & 71 & 30 & 8 \\
\hline 3570 & York Region & 0 & 0 & 1 \\
\hline 3595 & City of Toronto & N/A & N/A & N/A \\
\hline \multicolumn{5}{|l|}{ Niagara Peninsula } \\
\hline 3527 & Brant County & 30 & 30 & 10 \\
\hline 3534 & Haldimand-Norfolk & 43 & 43 & 7 \\
\hline 3537 & Hamilton-Wentworth & 17 & 83 & 6 \\
\hline 3546 & Niagara Region & 0 & 100 & 2 \\
\hline \multicolumn{5}{|l|}{ Southeast Region } \\
\hline 3535 & Haliburton-Kawartha-Pine Ridge & 0 & 33 & 3 \\
\hline 3538 & Hastings and Prince Edward Counties & 100 & 0 & 1 \\
\hline 3541 & Kingston-Frontenac-Lennox \& Addington & 100 & 0 & 2 \\
\hline 3555 & Peterborough County & 100 & 0 & 1 \\
\hline \multicolumn{5}{|l|}{ East Region } \\
\hline 3543 & Leeds-Grenville-Lanark District & 91 & 9 & 22 \\
\hline 3551 & Ottawa Carleton & 19 & 81 & 22 \\
\hline 3558 & Eastern Ontario & 91 & 9 & 35 \\
\hline
\end{tabular}

PHU, Public Health Unit; N/A, not applicable. 
bovine cryptosporidiosis were found in all but six PHU areas, and the raw farm prevalence estimate for Southern Ontario was $45 \%$, with PHU area-specific prevalence estimates ranging from $0 \%$ to $62 \%$ of the farms. Given the large number of cattle farms concentrated in Southern Ontario and how common calf diarrhoea is on cattle farms, the detection of cryptosporidiosis amongst the cattle population in this area is not surprising, as also noted by Trotz-Williams et al. (2005a).

A high-risk cluster of bovine cryptosporidiosis (RR 1.30, $\mathrm{P}=0.026$ ) was identified in the Central West region of Southern Ontario. The cluster encompassed the PHU areas of Bruce-GreyOwen Sound, Wellington-Dufferin Guelph, Huron and Waterloo, indicating that cattle within these areas were at a higher than expected risk for bovine cryptosporidiosis, compared to the risk outside of the cluster. The Central West region of Southern Ontario is known for having a high density of dairy cattle, which may potentially explain the higher bovine cryptosporidiosis risk seen in the cattle population (Statistics Unit, Ontario Ministry of Agriculture, Food and Rural Affairs, Statistics Canada, 2017). As previously mentioned, cryptosporidiosis predominantly affects dairy calves, causing severe diarrhoea that can lead to death (O'Donoghue, 1995; Abeywardena et al., 2015). Given the associated production loss that can result from this disease, infection, prevention and control strategies to reduce bovine cryptosporidiosis need to target this region of the province.

This study is subject to some limitations due to the data source used for analysis and the process for spatial aggregation. Because the prevalence of bovine cryptosporidiosis for Southern Ontario was determined using laboratory data from the AHL at the University of Guelph, the estimated prevalence may be biased by clinic-to-clinic differences in veterinary testing practices. As well in Southern Ontario, the AHL is not the only facility capable of providing diagnostic testing for cryptosporidiosis and proximity may play a role in the decision by veterinarians where to submit their samples for testing. Thirdly, since it is highly uncommon for cattle diarrhoea cases to result in diagnostic testing; submissions to the AHL for diagnostic testing usually occurs because of unusual signs, multiple calves in a herd presenting with diarrhoea, or more general herd outbreaks. Because of this, the estimated prevalence rates reported here may only reflect severe and unusual presentations of bovine cryptosporidiosis and not the prevalence in the general cattle farm population of Southern Ontario. In other words, it is likely that these estimates underestimate the true burden of cryptosporidiosis in the cattle farm population of Southern Ontario.

Another study limitation involves the method used to aggregate specimens of bovine cryptosporidiosis into PHU areas. As mentioned, the postal codes of the veterinary clinics submitting the specimens were used as a proxy for farm location to geographically aggregate the data. Since postal codes can include more than one PHU area, a single link indicator provided by Statistics Canada's PCCF was used to create a one-to-one relationship between the postal code and a PHU area. The actual street addresses of the clinics were not available; therefore, it was not possible to ascertain that all the clinics (and thus the farms) were aggregated to the correct PHU areas (Statistics Canada, 2016). Based on the misclassification assessment between owner and veterinarian location, using location of veterinary clinic as a proxy for the assumed location of exposure (farm location) may have resulted in potential misclassification of approximate $46 \%$ of the farms. This misclassification is likely to be non-differential since it is improbable that farms were more likely to be misclassified based on disease status. Non-differential misclassification blurs the true spatial pattern of the disease making it more difficult to identify a cluster (Berke and Waller, 2010). Therefore, since a cluster was identified in this study, it is likely that the risk in the population of the identified cluster is higher than what was estimated, i.e., that the risk ratio was biased away from the null.

Despite these limitations, it is important to note that based on laboratory diagnostic data, this study provided an estimate of the current burden of bovine cryptosporidiosis in the Southern Ontario cattle farm population. In addition, this is the first study to describe the spatial distribution of bovine cryptosporidiosis amongst the Southern Ontario cattle farm population. Finally, a high-risk cluster of bovine cryptosporidiosis was identified in the Central West region of Southern Ontario - an area known for having a high density of dairy cattle (Statistics Unit, Ontario Ministry of Agriculture, Food and Rural Affairs and Statistics Canada, 2017). Given the known association between neonatal calf diarrhoea and Cryptosporidium, and the impact this parasite can have on Ontario dairy operations, further studies that seek to understand the transmission patterns of this disease within and between the animal and human populations of this area, and the potential epidemiological factors that contribute to these patterns, are necessary.

\section{Conclusions}

Cryptosporidiosis is an infectious disease of relevance to the cattle industry because it has the potential to result in economic and production loss directly through cattle mortality and indirectly through decreased milk production, increased susceptibility to other diseases, treatment costs and poor growth (Peter et al., 2015; Senturk et al., 2016). In addition, there is a known risk of zoonotic transmission of Cryptosporidium in cattle to humans, with a resulting impact on public health (Trotz-Williams et al., 2006). Overall, the results from this study add to the existing body of evidence that Cryptosporidium is prevalent on cattle farms across Southern Ontario. Given the relationship between high livestock density and infectious diseases in cattle, and the implications of this relationship on both human health and the environment, further targeted surveillance studies should be conducted to understand the distribution and transmission of this disease among animals on Southern Ontario cattle farms and between the animal and human populations of the area.

\section{References}

Abeywardena H, Jex AR, Gasser RB, 2015. A perspective on Cryptosporidium and Giardia, with an emphasis on bovines and recent epidemiological findings. Adv Parasitol 88:243-301.

Berke O, 2001. Choropleth mapping of regional count data of Echinococcus multilocularis among red foxes in Lower Saxony, Germany. Prev Vet Med 52:119-31.

Berke O, 2005. Exploratory spatial relative risk mapping. Prev Vet Med 71:173-82.

Berke O, Waller L, 2010. On the effect of diagnostic misclassification bias on the observed spatial pattern in regional count data-a case study using West Nile virus mortality data from Ontario, 2005. Spat Spatiotemporal Epidemiol 1:117-22.

Bishop-Williams KE, Berke O, Pearl DL, Kelton DF, 2016. Mapping rural community and dairy cow heat stress in Southern Ontario: A common geographic pattern from 2010 to 2012. Arch Environ Occup Health 71:199-207. 
Bivand R, Altman M, Anselin L, Assunção R, Berke O, Bernat A, Blanchet G, 2015. Package 'spdep'.

Bivand R, Hauke J, Kossowski T, 2013. Computing the Jacobian in Gaussian spatial autoregressive models: an illustrated comparison of available methods. Geogr Anal 45:150-79.

Bivand R, Lewin-Koh N, 2013. Maptools: tools for reading and handling spatial objects. R Package version 0.8-23.

Buhnerkempe MG, Tildesley MJ, Lindstrom T, Grear DA, Portacci $\mathrm{K}$, Miller RS, Lombard JE, Werkman M, Keeling MJ, Wennergren U, Webb CT, 2014. The impact of movements and animal density on continental scale cattle disease outbreaks in the United States. PloS One 9:e91724.

Coklin T, Uehlinger FD, Farber JM, Barkema HW, O’Handley RM, Dixon BR, 2009. Prevalence and molecular characterization of Cryptosporidium spp. in dairy calves from 11 farms in Prince Edward Island, Canada. Vet Parasitol 160:323-6.

Dohoo I, Martin W, Stryhn H, 2012. Measures of disease frequency. In: Dohoo I, Martin W, Stryhn H, eds. Methods in epidemiologic research. VER Inc, Charlottetown, Prince Edward Island, pp 7794

Environmental Management Branch, OMAFRA, 2016. 2011 census agricultural maps. Available from: http://www.omafra.gov. on.ca/english/landuse/gis/census_livestock.htm

Fayer R, Santin M, Trout JM, 2008. Cryptosporidium ryanae n. sp. (apicomplexa: Cryptosporidiidae) in cattle (Bos taurus). Vet Parasitol 156:191-8.

French J, 2015. Smerc: statistical methods for regional counts. R package version $0.2 .2 \mathrm{ed}$.

Goovaerts P, 2006. Geostatistical analysis of disease data: accounting for spatial support and population density in the isopleth mapping of cancer mortality risk using area-to-point poisson kriging. Int J Health Geogr 5:52.

Hampton KH, Serre ML, Gesink DC, Pilcher CD, Miller WC, 2011. Adjusting for sampling variability in sparse data: geostatistical approaches to disease mapping. Int J Health Geogr 10:54.

Mann ED, Sekla LH, Nayar GP, Koschik C, 1986. Infection with Cryptosporidium spp. in humans and cattle in Manitoba. Can J Vet Res 50:174-8.

Marshall RJ, 1991. Mapping disease and mortality rates using empirical bayes estimators. J R Stat Soc Ser C Appl Stat 40:283-94.

O’Donoghue PJ, 1995. Cryptosporidium and cryptosporidiosis in man and animals. Int J Parasitol 25:139-95.

Olson ME, Guselle NJ, O'Handley RM, Swift ML, McAllister TA, Jelinski MD, Morck DW, 1997. Giardia and Cryptosporidium in dairy calves in British Columbia. Can Vet J 38:703-6.

Ontario Ministry of Government and Consumer Services, 2017. Maps of Southern Ontario by geographical location. Ontario Ministry of Government and Consumer Services, Ontario, Canada. Available from: http://www.archives.gov.on.ca/en /maps/counties/region.aspx Accessed: November 26, 2017.

Ouchene N, Ouchene-Khelifi NA, Khelifi M, Zeroual F, Bitam I, Benakhla A, AbuMedian AB, 2016. Prevalence and molecular characterization of Cryptosporidium in dairy cattle from farms in Algeria. Kafkas Universitesi Veteriner Fakultesi Dergisi 22:7037.

Peter GS, Gitau GK, Mulei CM, Vanleeuwen J, Richards S, Wichtel J, Uehlinger F, Mainga O, 2015. Prevalence of Cryptosporidia, Eimeria, Giardia, and Strongyloides in pre-weaned calves on smallholder dairy farms in Mukurwe-ini district, Kenya. Vet World 8:1118-25.

R Core Team, 2016. R: A language and environment for statistical computing. R Foundation for Statistical Computing, Vienna, Austria.

RStudio Team, 2016. RStudio: Integrated development for R. RStudio, Inc, Boston, MA.

Reiczigel J, Foldi J, Ozsvari L, 2010. Exact confidence limits for prevalence of a disease with an imperfect diagnostic test. Epidemiol Infect 138:1674-8.

Ribeiro Jr PJ, Diggle PJ, 2001. GeoR: a package for geostatistical analysis. R News 1:14-8.

Rogan WJ, Gladen B, 1978. Estimating prevalence from the results of a screening test. Am J Epidemiol 107:71-6.

Ruest N, Faubert GM, Couture Y, 1998. Prevalence and geographical distribution of Giardia spp. and Cryptosporidium spp. in dairy farms in Quebec. Can Vet J 39:697-700.

Senturk S, Catk S, Temzel EM, Ozygt O, 2016. Outbreak of bovine papular stomatitis with concurrent cryptosporidiosis in a dairy herd in Turkey. Bulg J Vet Med 19:78-83.

Sivajothi S, Reddy BS, Rayulu VC, 2014. Cryptosporiodiosis in neonatal dairy calves. Adv Appl Sci Res 5:74-6.

Statistics Canada, 2014. Snapshot of Canadian agriculture. Statistics Canada, Ottawa, Ontario, Canada. Available from: http://www.statcan.gc.ca/ca-ra2006/articles/snapshot-portraiteng.htm

Statistics Canada, 2016. Postal code conversion file (PCCF), reference guide 2015. Statistics Canada catalogue no.92-154-X. Statistics Canada, Ottawa, Ontario, Canada.

Statistics Canada, Canadian Dairy Commission, 2016. Number of farms, dairy cows and heifers. Canadian Dairy Information Centre, Ottawa, Ontario, Canada. Available from: http://www.dairyinfo.gc.ca/index_e.php?s1=dff-fcilands2=farmfermeands $3=n b$

Statistics Unit, Ontario Ministry of Agriculture, Food and Rural Affairs, Statistics Canada, 2017. Livestock and poultry statistics. Ministry of Agriculture, Food and Rural Affairs, Canada. Available from: http://www.omafra.gov.on.ca/english/stats/livestock/index.html Accessed: June 7, 2017.

Tango T, Takahashi K, 2005. A flexibly shaped spatial scan statistic for detecting clusters. Int J Health Geogr 4:11.

Trotz-Williams LA, Jarvie BD, Martin SW, Leslie KE, Peregrine AS, 2005a. Prevalence of Cryptosporidium parvum infection in Southwestern Ontario and its association with diarrhea in neonatal dairy calves. Can Vet J 46:349-51.

Trotz-Williams LA, Martin DS, Gatei W, Cama V, Peregrine AS, Martin SW, Nydam DV, Jamieson F, Xiao L, 2006. Genotype and subtype analyses of Cryptosporidium isolates from dairy calves and humans in Ontario. Parasitol Res 99:346-53.

Trotz-Williams LA, Martin SW, Leslie KE, Duffield T, Nydam DV, Peregrine AS, 2007. Association between management practices and within-herd prevalence of Cryptosporidium parvum shedding on dairy farms in Southern Ontario. Prev Vet Med 83:11-23.

Trotz-Williams LA, Martin SW, Martin D, Duffield T, Leslie KE, Nydam DV, Peregrine AS, 2005b. Multiattribute evaluation of two simple tests for the detection of Cryptosporidium parvum in calf faeces. Vet Parasitol 134:15-23. 